\title{
Application of Multiple Detection Data in the Analysis of Snowstorm Processes in Xinjiang during the Central Asia Extreme Precipitation Observation Test (CAEPOT)
}

\author{
Yong Zeng $\mathbb{C}^{1,2}$ Lianmei Yang, ${ }^{1,2}$ Zepeng Tong, ${ }^{1,2}$ and Zuyi Zhang ${ }^{1,2}$ \\ ${ }^{1}$ Institute of Desert Meteorology, China Meteorological Administration, Urumqi 830002, China \\ ${ }^{2}$ Center for Central Asian Atmosphere Science Research, Urumqi 830002, China \\ Correspondence should be addressed to Yong Zeng; 15099610397@163.com
}

Received 21 August 2020; Revised 20 November 2020; Accepted 9 December 2020; Published 21 December 2020

Academic Editor: Hiroyuki Hashiguchi

Copyright (c) 2020 Yong Zeng et al. This is an open access article distributed under the Creative Commons Attribution License, which permits unrestricted use, distribution, and reproduction in any medium, provided the original work is properly cited.

\begin{abstract}
At present, there is insufficient research on the refinement of the vertical structure of winter snowstorm systems in arid areas, and, compared with the central and eastern China, the observation sites in arid areas of northwestern China are scarce. To deepen the understanding of dynamics and microphysical processes and improve the level of forecasting and warning of snowstorms in northwestern China, the Institute of Desert Meteorology, China Meteorological Administration, Urumqi, carried out the Central Asia Extreme Precipitation Observation Test (CAEPOT) in Yili, Xinjiang, a typical arid region in China in February 2020. This paper uses multiple fine detection datasets obtained from the CAEPOT, including radar wind profiler, ground-based microwave radiometer, and millimeter-wave cloud radar to analyze macroscopic characteristics and microphysical changes of snowstorm system in Xinjiang. Studies have shown that the low trough with sufficient moisture, heat, power conditions, and weakening banded cloud system, which moved eastward from the Aral Sea to the west of Xinjiang during the snowstorm, were the key influencing system of this snowstorm. Before the snowstorm, the vertical shear of the horizontal wind field was severe, which aggravated the instability of the atmosphere, and there was upward motion in the lower atmosphere. A variety of physical quantities related to moisture showed a tendency to increase at the lower level and could be used as an early warning signal for snowstorm about 8 hours in advance, and the cloud and snow particles observed by millimeter-wave cloud radar were simultaneously developing upward and downward from $4 \mathrm{~km}$, providing snowstorm warning 12 hours in advance. During the snowstorm, the horizontal wind speed and vertical speed were obviously enhanced, and the physical quantities related to moisture further increased, and, with the blocking and uplifting of the Tianshan Mountains, the snowstorm increased. The particles collided and grew while falling, resulting in a decrease in particle concentration and an increase in particle radius from high altitude to the ground, eventually resulting in near-ground reflectivity factor up to $30 \mathrm{dBz}$. In addition, reflectivity factor, physical quantities related to moisture, wind field, particle concentration, and particle radius all had a good correspondence with the beginning, end, and intensity of snowstorm, so when the physical quantities mentioned above weakened and stopped, snowstorm also weakened and stopped. In a word, this research is an important and meaningful work that provides more backgrounds and references for the forecast and warning of snowstorm in northwestern China.
\end{abstract}

\section{Introduction}

A radar wind profiler is a new wind measurement device that can provide a continuous distribution of data on meteorological elements such as the horizontal atmospheric wind field, the vertical airflow, and the atmospheric refractive index structure constant over the altitudinal profile. The type of the observed system can be determined from the change in the vertical profile over time, such as grooves, ridges, fronts, shear lines, and gravity waves [1-5]. Radar wind profiler data have been widely applied to the research and forecasting and warning operations for severe weather, including typhoons, heavy rain, and strong convection [6-12]. Other researchers have used radar wind profiler to study 
atmospheric turbulence and boundary layer meteorology [13-16]. The application and research on radar wind profiler during the process of snowstorms have also made many achievements [17-19]. However, the research on radar wind profiler data during snowstorms in arid regions of China is still lacking.

Ground-based microwave radiometers can detect the continuous vertical profiles of meteorological elements such as atmospheric temperature, relative humidity, and water vapor density by receiving microwave radiation from a certain wave band of the atmosphere. Atmospheric temperature and humidity information detected by microwave radiometers have been widely used in atmospheric detection research [20-23]. The integrated water vapor and cloud water content detected by a microwave radiometer also play an important role in reflecting the continuous changes in atmospheric water vapor [24, 25]. Revercomb et al. [26] summarized the research background and prospect of using a microwave radiometer to detect water vapor in the Atmospheric Radiation Measurement test in the United States. However, the application of ground-based microwave radiometers during snowstorms in arid areas of China needs further study.

Millimeter-wave cloud radar exhibits both good sensitivity and spatial resolution. This type of radar can not only detect the fine particle structure and microphysical characteristics of clear sky clouds but also be used for macroscopic structure observations and microphysical parameter inversion of weak precipitation or snowfall systems. With the advancement of technology, millimeterwave radar plays an important role in the study of cloud and precipitation physics. The $35 \mathrm{GHz}$ millimeter-wave cloud radar (MMCR) developed by the Atmospheric Radiation Measurement (ARM) Program and the dual wavelength (W/Ka band) cloud radar developed by University of Massachusetts in the United States are used to detect the microphysical characteristics of clouds [27, 28]. Scientists at University of Colorado and the Earth System Research Laboratory of NOAA in the United States used eight-millimeter radar to detect snowfall and experimental data and theoretical research to obtain snowfall estimation formulas. The formulas were compared, and an error analysis was performed to illustrate the feasibility [29]. Liao et al. [30] used $\mathrm{Ku} / \mathrm{Ka}$-band dual-frequency radar to complete the particle size distribution (PSD) hypothesis by exploring appropriate scattering models and appropriate particle size distributions, focusing on the microphysical properties of snow. In China, the research and development of millimeter-wave radar are relatively lagging. Researchers have carried out meaningful research in only central and eastern China and the Tibetan Plateau [31-34]; however, this type of research is of great significance for understanding the physical characteristics of clouds and precipitation in China. However, the application of millimeter-wave cloud radar to evaluation of the snowstorm process in arid regions of China is still lacking.

Xinjiang is located in central Asia, and the climate in this region is different from the significant monsoon climate caused by the monsoon system in central and eastern China.
Xinjiang is not directly affected by the monsoon system, resulting in a typical arid climate $[35,36]$. At the same time, the Tianshan Mountains, Altay Mountains, Kunlun Mountains, Taklimakan Desert, Gurbantunggut Desert, and human settlements in Xinjiang have formed a special high mountain-oasis-desert system. The Tianshan Mountains have important and profound impacts on the weather and climate in Xinjiang (Figure 1(a)). In the past, some researchers had conducted research on Xinjiang snowstorm. Zhuang et al. [37] pointed out that the number and duration of mesoscale cold cloud clusters were proportional to the amount of snowfall and that the snowstorm corresponded well to the reflectance factor above $15 \mathrm{dBz}$, and the strongest reflectivity factor basically coincided with the snowstorm center, so their research had provided some references for the forecast and warning of snowstorms in Xinjiang. However, their research was only based on conventional data such as Doppler weather radar, FY satellite, and reanalysis data, so it cannot provide more details of the snowstorm process. More importantly, due to the steep terrain, Doppler weather radar observations were blocked to a certain extent by the Tianshan Mountains. Therefore, the vertical observation equipment had obvious advantages in Xinjiang. Wang et al. [38,39] used a vertically directed radar wind profiler and a microwave radiometer to conduct research on the snowstorm in Urumqi, Xinjiang. Their researches showed that the radar wind profiler had a certain reference value for the forecast and warning of the snowstorm; in particular, some physical quantities calculated from the power spectrum data of the radar wind profiler had reference significance in forecasting and warning snowstorms. However, their research area was Urumqi, Xinjiang, which was quite different from the topography of the Yili area, and millimeter-wave cloud radar was not used in their research, which limited the research on the microphysical process of snowfall. During the frequent southward movement of polar front jets in winter, Xinjiang has become one of the three largest snowfall regions in China in winter, and the Yili area is affected by the terrain of the Tianshan Mountains and is the snowfall center of Xinjiang [40]. Therefore, further revealing the fine structure and changes of the snowstorm process is of great significance for the forecast and warning of snowstorms in northwestern China. However, precise and comprehensive observations of snowfall in Xinjiang have not been carried out because of the lack of observation instruments, and the macroscopic characteristics and microphysical changes to the snowstorm process in China's arid regions are not well understood. Based on the above reasons, the Institute of Desert Meteorology, China Meteorological Administration, Urumqi, carried out the Central Asia Extreme Precipitation Observation Test (CAEPOT) in Yili, Xinjiang, in February 2020. The observation instruments are located at the Xinyuan station in Yili, including a radar wind profiler, ground-based microwave radiometer, and millimeter-wave cloud radar (Figure 1(b)). The data obtained by these observation instruments are used to make a preliminary analysis of a snowstorm process to provide some beneficial reference for the early warning of snowstorms in this area. 


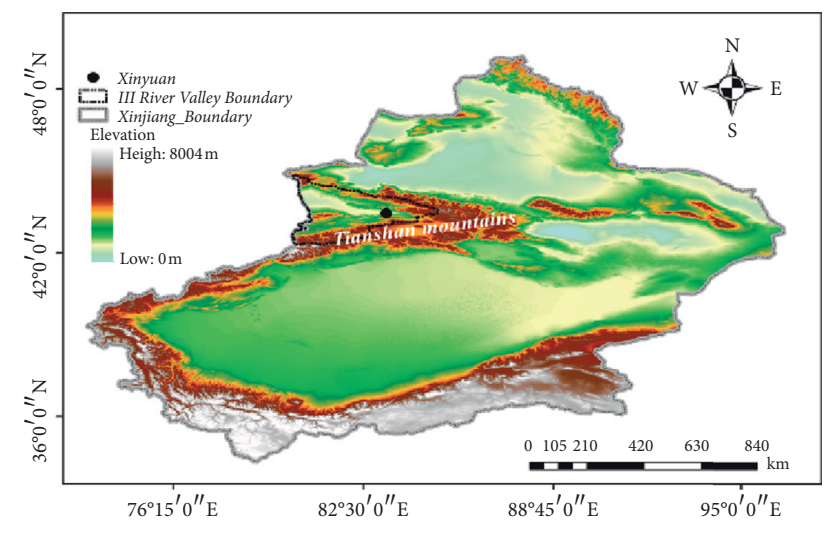

(a)

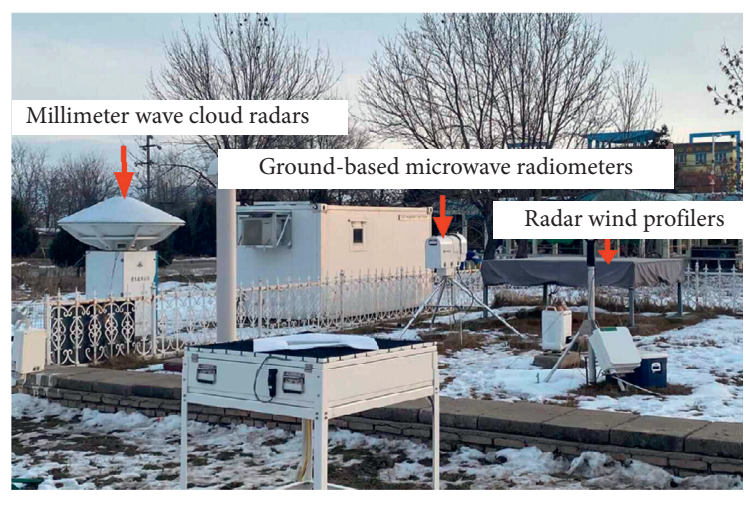

(b)

Figure 1: (a) The location of the test area in Xinjiang. (b) Photograph of the test instruments.

\section{Data and Methods}

The data used in this research include hourly snowfall data from ground weather stations in the Yili region of Xinjiang, temperature of black body (TBB) data from FY-2G, radar wind profiler data, microwave radiometer data, and millimeter-wave cloud radar data.

The radar wind profiler used in this study was manufactured by the No. 23 Research Institute of China Aerospace Science and Industry Corporation, and these profiles mainly consist of a transmitter, antenna, monitoring system, receiver, signal processing and control unit, and data processing package. The profiler can output 51 layers of horizontal wind, vertical velocity, and atmospheric refractive index structure constant data from $60 \mathrm{~m}$ to $5280 \mathrm{~m}$ in the vertical direction. The measurement interval is $60 \mathrm{~m}$ between heights of $60 \mathrm{~m}$ and $840 \mathrm{~m}$, and the interval is $120 \mathrm{~m}$ above $840 \mathrm{~m}$. The data have three kinds of temporal resolutions: $6 \mathrm{~min}, 0.5 \mathrm{~h}$, and $1 \mathrm{~h}$. The data used in this paper have a $1 \mathrm{~h}$ time resolution.

The 35-channel MP-3000A microwave radiometers produced by Radiometrics Corporation, USA, were used in this study. The observed brightness temperature data were used for inversions in the neural network, and humidity, temperature, and water vapor profile data were output in 58 layers from the ground to a height of $10 \mathrm{~km}$ in the zenith direction. The vertical resolution of the profile is $50 \mathrm{~m}$ below $500 \mathrm{~m}, 100 \mathrm{~m}$ from 0.5 to $2 \mathrm{~km}$, and $250 \mathrm{~m}$ above $2 \mathrm{~km}$.

The millimeter-wave cloud radar used in this study was produced by the No. 23 Research Institute of China Aerospace Science and Industry Corporation and is a $\mathrm{Ka}$ band radar ( $8 \mathrm{~mm}$ wavelength), which adopts an all solidstate, all coherent, pulse Doppler, pulse compression, single shot single-line polarization system. The radar consists of an antenna, a transceiver module, a digital receiver, and a power-on module. The antenna diameter is $1.8 \mathrm{~m}$, the vertical resolution is $30 \mathrm{~m}$, the temporal resolution is $1 \mathrm{~min}$, and the detection height is $20 \mathrm{~km}$.

\section{Results}

3.1. Snowfall Facts. The standard for the identification of a snowstorm in China is that the 24-hour snowfall is greater than $10 \mathrm{~mm}$. However, the standard for the definition of a snowstorm in the arid area of Xinjiang is that the 24-hour snowfall exceeds $12 \mathrm{~mm}$ [41], which is also in line with the fact that Xinjiang is one of the centers of snowstorms in China. Between 06:00 on February 18 and 06:00 on February 19 in 2020 (universal time, the same below), a notable snowstorm occurred in the Yili area. In the Yili area, there are 10 national automatic weather stations (National AWSs), but the snowfall was unevenly distributed during this event. Snowstorms were mainly concentrated at the Xinyuan station, with a snowfall of $13.3 \mathrm{~mm}$, and the snowfall period was mainly from 11:00 on February 18 to 05:00 on February 19 in 2020 at the Xinyuan station (Figure 2). In addition, except for the Turks station, which experienced heavy snow (snowfall of $8.4 \mathrm{~mm}$ ), the other eight stations experienced little-to-moderate snow, and the distribution of snowfall exhibited a certain mesoscale feature.

3.2. Weather Situation. Before the snowstorm occurred, the Xinjiang region at $500 \mathrm{hPa}$ was controlled by a ridge of high pressure, with a low trough in the Aral Sea at 18:00 on February 17, 2020 (Figure 3(a)). During the eastward shift of the low trough, the low trough was located near Balkhash Lake, the Yili area was controlled by the northwest-southwest trough in front of the southwest jet stream, and obvious snowfall began to appear at $12: 00$ on February 18 (Figure 3(b)). As the trough moved further east, the low trough had moved past the Yili area at 06:00 on February 19, and the northwest airflow behind the trough controlled the area and the snow stopped (Figure 3(c)). At the same time, the Yili area was located to the left of a high-level jet outlet area, the intensity of the jet center exceeded $60 \mathrm{~ms}^{-1}$ (Figure 3(d)), studies have shown that high-level jets are beneficial to the formation of divergence in the upper atmosphere [42], and strong divergence was conducive to the formation of snowstorms.

\subsection{Water Vapor and Thermal and Dynamic Conditions.} For the occurrence of snowstorms, it is necessary to have appropriate weather-scale circulation, while favorable water vapor and thermal and dynamic conditions are also very 


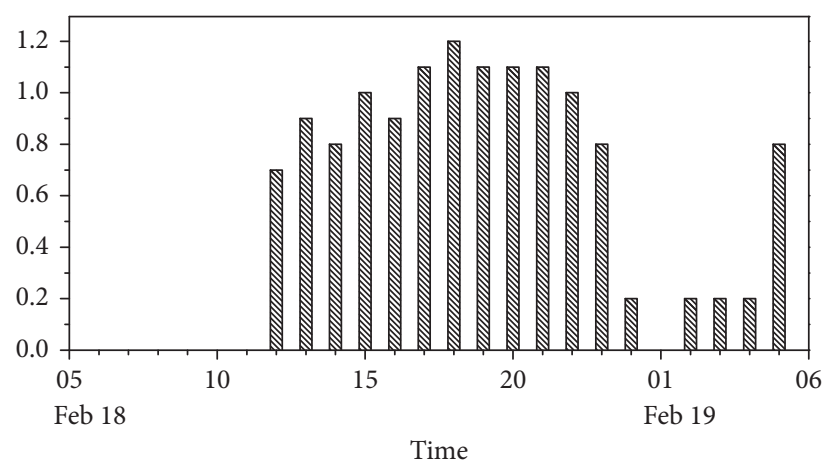

FIgURe 2: Hourly snowfall at the Xinyuan station (unit: $\mathrm{mm}$ ).

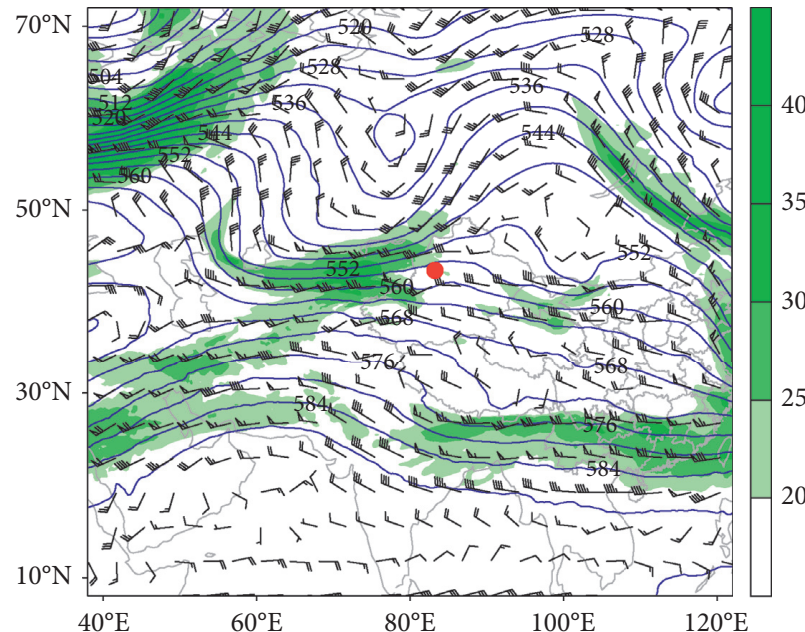

(a)

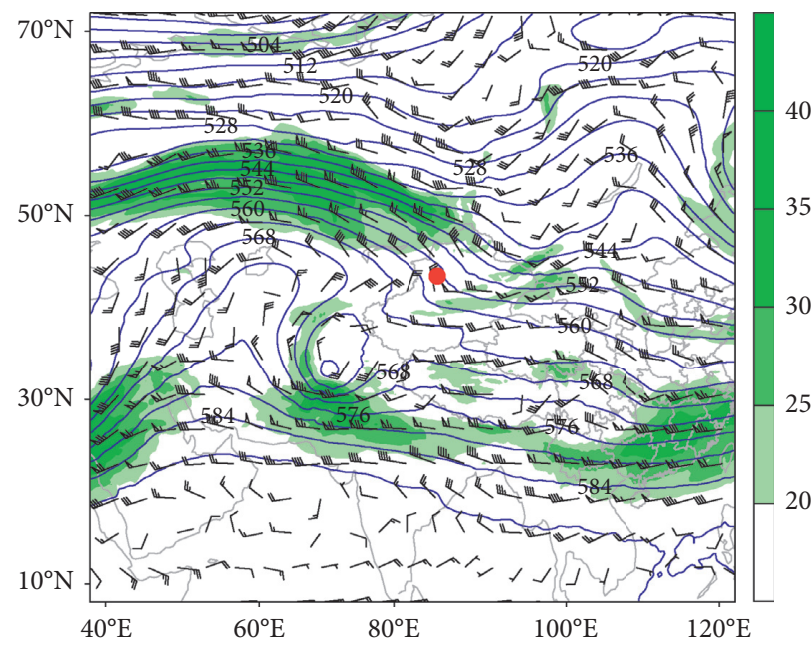

(c)

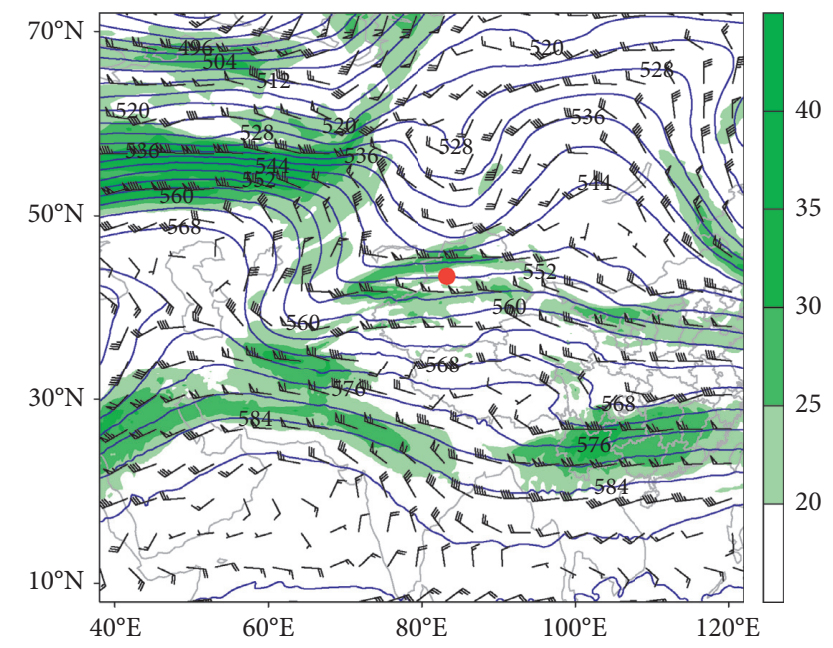

(b)

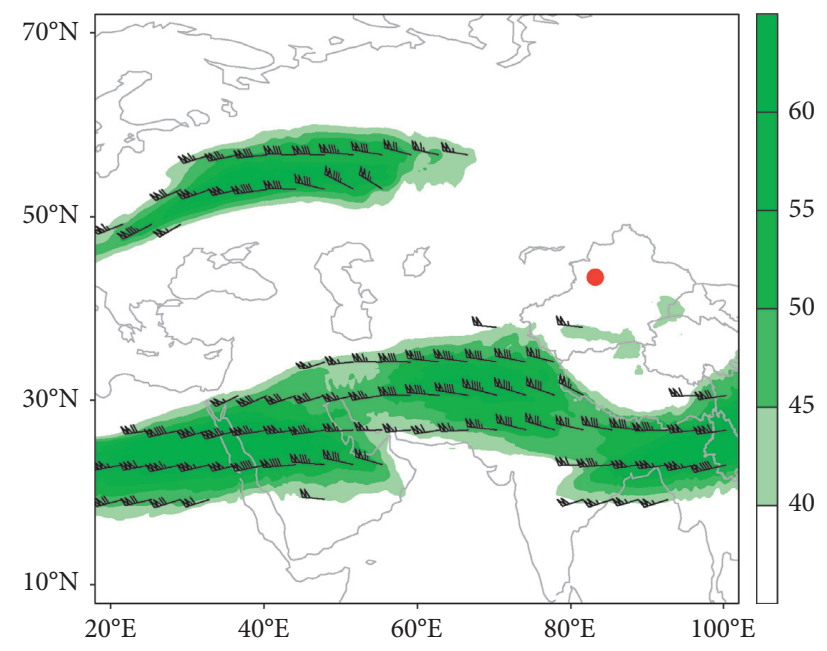

(d)

FIGURE 3: The geopotential height (blue solid line; unit, dagpm), wind field (wind pole; unit, $\mathrm{ms}^{-1}$ ), jet stream (shadow; unit, ms ${ }^{-1}$ ) at $500 \mathrm{hPa}$ (a) at 18:00 on February 17, (b) at 12:00 on February 18, (c) at 06:00 on February 19, 2020, and (d) high-altitude jet stream (shadow; unit, $\mathrm{ms}^{-1}$ ) at $200 \mathrm{hPa}$ (the red spot represents the Xinyuan station).

important. The time-height profile of the specific humidity during this snowstorm process shows that the water vapor was mainly below $600 \mathrm{hPa}$, and, approximately $6 \mathrm{~h}$ before the start of the snowstorm, the specific humidity began to increase at the near surface. At the beginning of snowfall, the specific humidity increased to a maximum of $2.7 \mathrm{~g} \mathrm{~kg}^{-1}$, and after the snowfall was over, it quickly decreased (Figure 4(a)). Wu et al. [43] pointed out that, in the front 
zone with dense pseudoequivalent temperature $(\theta s e)$ contours in the lower layer, the dynamic forcing in the front zone is conducive to the upward transport of energy in the lower layer, and the steep vertical zone of $\theta$ se is prone to the slant development of vorticity. The time-height profile of $\theta$ se during the snowstorm process shows that when the snowstorm started, the low-level $\theta$ se was dense and showed an inclined distribution, which was conducive to the development of vorticity (Figure 4(b)). Correspondingly, the time-height profile of the vorticity showed that, during the snowstorm, the vorticity obviously developed (Figure 4(c)). At the same time, the time-height profile of the divergence showed that the divergence during the snowstorm process was characterized by low-level convergence and high-level divergence (Figure 4(d)). In summary, during the snowstorm, water vapor and thermal and dynamic conditions were well coordinated, which were conducive to the production of a snowstorm.

3.4. Cloud System Changes during the Snowstorm. Figure 5 shows the TBB data of FY-2G during the snowstorm process. At 12:00 on February 18, when snowfall began, the Xinyuan station was located in the front of the northeast-southwest banded cloud system (Figure 5(a)). As the cloud system moved eastward, the Xinyuan station was affected by the band cloud system with a smaller scale from 12:00 to 16:00 on February 18 (Figure 5(b)). In the process of further eastward movement, the scale of the cloud system affecting the Xinyuan station was further reduced at 19:00 on February 18 (Figure 5(c)). After 00:00 on February 19, the high-level cloud system left the Xinyuan station during the eastward movement, and the Xinyuan station was mainly controlled by the more stable subhigh layer cloud system (Figure 5(d)-5(f)), and the snowfall intensity weakened at this stage. At the same time, the distribution of the subhigh layer cloud system corresponded to the terrain of the Tianshan Mountains, so the Tianshan Mountains played an important role in the snowfall process.

3.5. Radar Wind Profiler Data Analysis. Figure 6(a) shows the time-height profile of the horizontal wind of the radar wind profiler during the snowstorm. At 20:00 on February 17 before the start of the snowstorm, the horizontal wind below $2000 \mathrm{~m}$ changed from a westerly wind to an easterly wind, while the westerly wind above $2000 \mathrm{~m}$ was maintained. The increased vertical shear of the horizontal wind led to increased atmospheric instability, which was conducive to the occurrence of a snowstorm. At $03: 00$ on February 18, the horizontal winds from the lower to the upper levels were northerly, easterly, westerly, northerly, and westerly winds, and the wind direction changed drastically, which was conducive to the maintenance and development of atmospheric instability. From $05: 00$ to $12: 00$ on February 18, the northerly wind was obvious at an altitude of approximately $2520 \mathrm{~m}$, and the wind direction reversed significantly with increasing altitude, indicating strong cold advection. Snowstorm began to appear after 11:00 on February 18, the entire atmosphere was dominated by westerly winds, the wind speed in the middle and low layers increased significantly, and cold advection was still obvious. At the same time, the snowstorm area was controlled by the southwest airflow from the east of the trough moving eastward. After the lower-level strengthened westerly wind met the Tianshan Mountains, a clear low-level convergence was formed in the snowstorm area as shown in Figure 4(d), which is conducive to the enhancement of the snowstorm.

Figure 6(b) is the time-height profile of the vertical velocity of the radar wind profiler during the snowstorm. Before the start of the snowstorm, there was ascending movement in the lower atmosphere, which was conducive to the production of a snowstorm. When the snowstorm was approaching, the sinking movement dominated. Throughout the snowstorm, the strongest sinking speed reached $1.1 \mathrm{~ms}^{-1}$, which was located at a height below $2520 \mathrm{~m}$.

Figure 6(c) shows the natural logarithm of the atmospheric refractive index structure constant of the radar wind profiler during the snowstorm. This function can describe the backscattering ability of atmospheric turbulence on electromagnetic waves, which is related to the radar wind profiler parameters, temperature, humidity, air pulsation, and other related factors. Before the start of the snowstorm, the natural logarithm of the atmospheric refractive index structure constant was small, basically less than -15 . When the snowstorm approached, the atmospheric instability increased, the humidity increased, and the natural logarithm of the atmospheric refractive index structure constant increased. The maximum value of the natural logarithm of the atmospheric refractive index structure constant reached -12.5 throughout the process, which is beneficial to the maintenance of snowfall.

\subsection{Analysis of Ground-Based Microwave Radiometer Data.} Figure 7(a) is the time-height profile of the temperature from the ground-based microwave radiometer during the snowstorm. Before the snowstorm began, the temperature remained basically unchanged throughout all layers of the atmosphere. After the start of the snowstorm, corresponding to the cold advection reflected by the radar wind profiler in Figure 6(a), the temperature of all atmosphere layers decreased, and the temperature decrease trend continued until approximately $2 \mathrm{~h}$ after the end of the snowfall.

Figure 7(b) is the time-height profile of the water vapor density of the ground-based microwave radiometer during the snowstorm. At 06:00 on February 18 before the start of the snowstorm, the maximum value of the water vapor density was less than $3.01 \mathrm{~g} \mathrm{~kg}^{-1}$, and it was located near the ground below $0.5 \mathrm{~km}$. Throughout the snowstorm, the water vapor density was mainly concentrated below $1.5 \mathrm{~km}$, and the maximum value of the water vapor density near the surface below $0.5 \mathrm{~km}$ exhibited good correspondence with the snowfall intensity. Before 23:00 on February 18, the water vapor density near the surface was relatively large, and the height was relatively high, corresponding to strong snowfall in Figure 2. After 23:00 on February 18, the nearsurface water vapor density decreased, the height decreased, and the intensity of snowfall weakened during this period. 


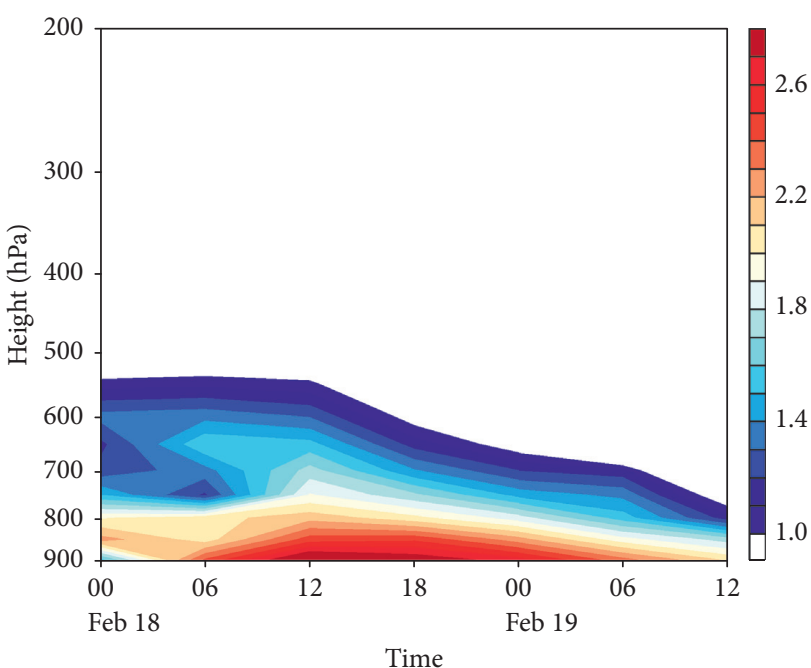

(a)

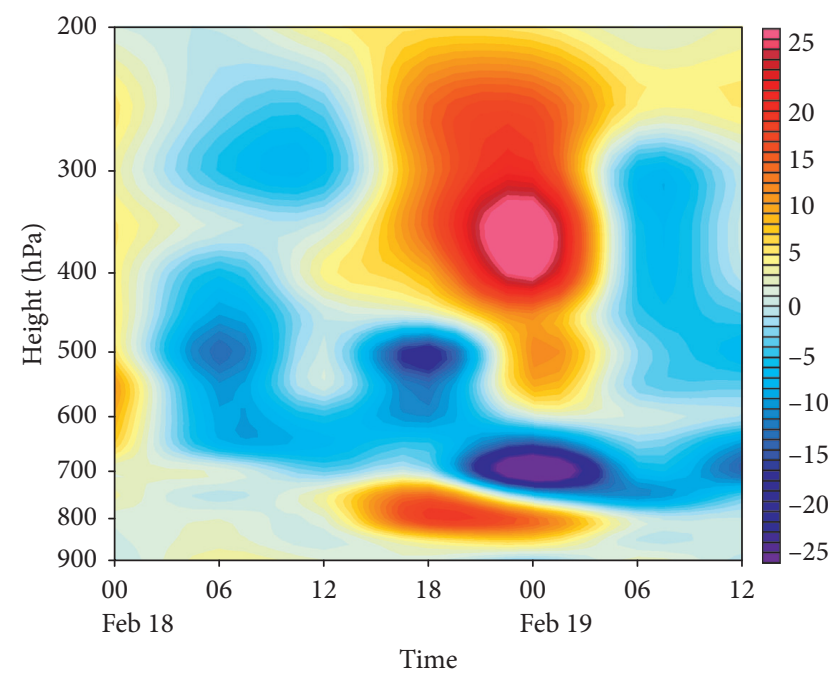

(c)

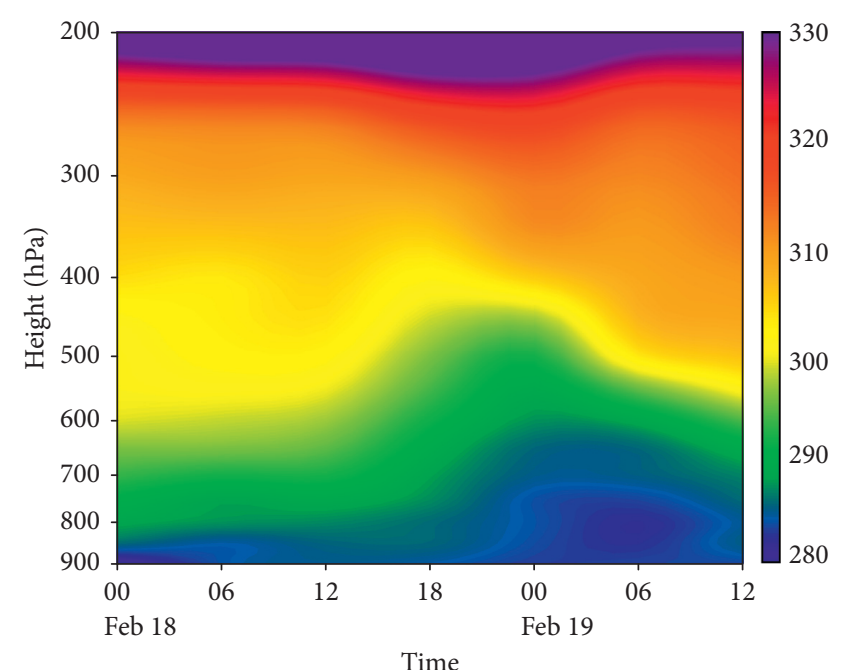

(b)

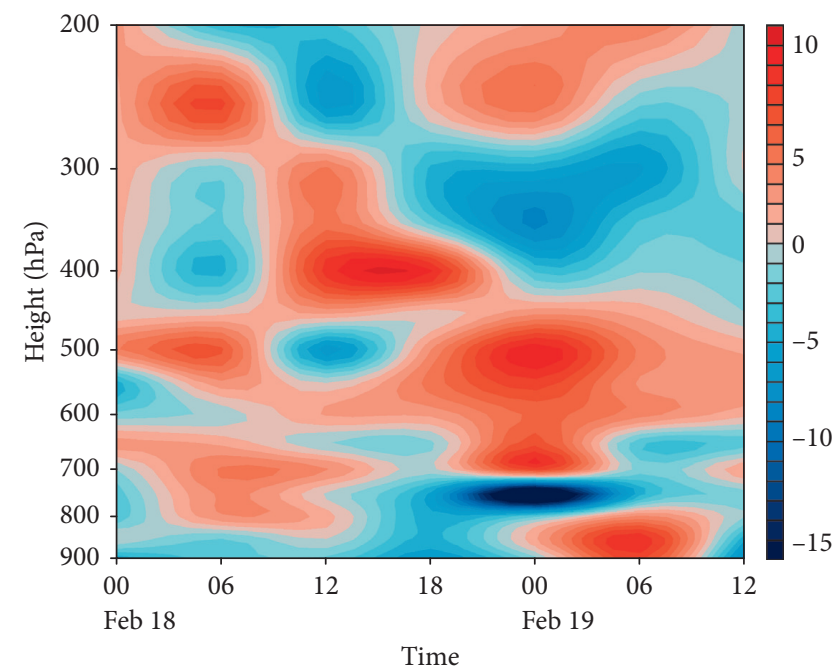

(d)

FIgURE 4: The time-height profile: (a) specific humidity (shadow; unit, $\mathrm{g} \mathrm{kg}^{-1}$ ), (b) pseudoequivalent temperature (shadow; unit, K), (c) vorticity (shadow; unit, $10^{-5} \mathrm{~s}^{-1}$ ), and (d) divergence (shadow; unit, $10^{-5} \mathrm{~s}^{-1}$ ).

After 05:00 on February 19, the water vapor density significantly weakened, and the snowfall stopped.

Figure $7(\mathrm{c})$ is the time-height profile of the relative humidity from the ground-based microwave radiometer during the snowstorm. At 11:00 on February 18 before the start of the snowstorm, the relative humidity below $3 \mathrm{~km}$ began to increase but did not reach saturation. During the snowstorm, the area with relative humidity greater than $50 \%$ was below $3 \mathrm{~km}$, and the height of the areas with more than $50 \%$ relative humidity gradually decreased. The $100 \%$ relative humidity area was located in the near-surface layer below $0.5 \mathrm{~km}$, and the relative humidity in the near-surface layer reached $100 \%$ approximately $2 \mathrm{~h}$ after the start of the snowstorm. After the snowstorm, the relative humidity decreased significantly. This pattern can be further seen from the curves of the average temperature, average relative humidity, and hourly precipitation during the snowfall process (Figure $7(\mathrm{~d})$ ). During the snowstorm process, the average temperature showed a decreasing trend due to cold advection, and the temperature decreased by $2^{\circ} \mathrm{C}$. The average relative humidity first increased and then decreased, and the relative humidity varied from $45 \%$ to $55 \%$.

3.7. Millimeter-Wave Cloud Radar Data Analysis. Figure 8(a) is the time-height profile of the reflectivity factor from the millimeter-wave cloud radar during the snowstorm. Before the start of the snowstorm, there was a weak reflectivity factor from 2 to $7 \mathrm{~km}$, which dissipated at 20:00 on February 17. At 00:00 on February 18, when the snowstorm approached, the reflectivity factor began to develop upward and downward simultaneously from $4 \mathrm{~km}$, and snowstorm started when the strong reflectivity factor reached the ground. The reflectivity factor was between $-30 \mathrm{dBz}$ and $30 \mathrm{dBz}$ during the snowstorm process, the strong reflectivity factor greater than $6 \mathrm{dBz}$ was below $4 \mathrm{~km}$, 


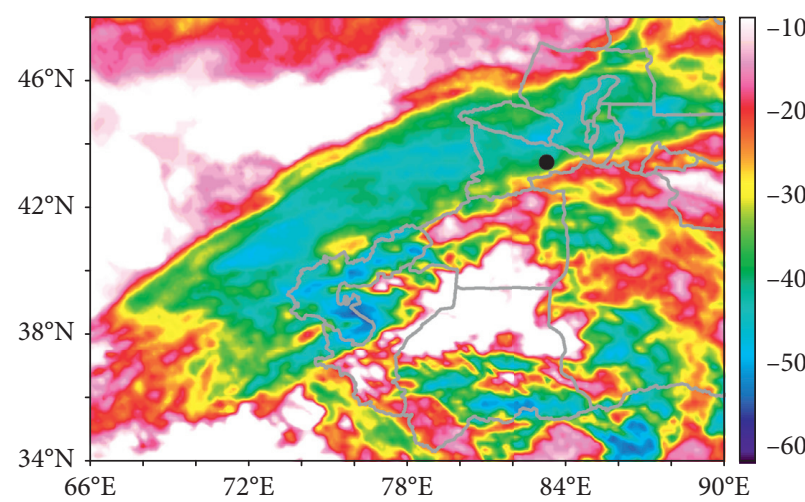

(a)

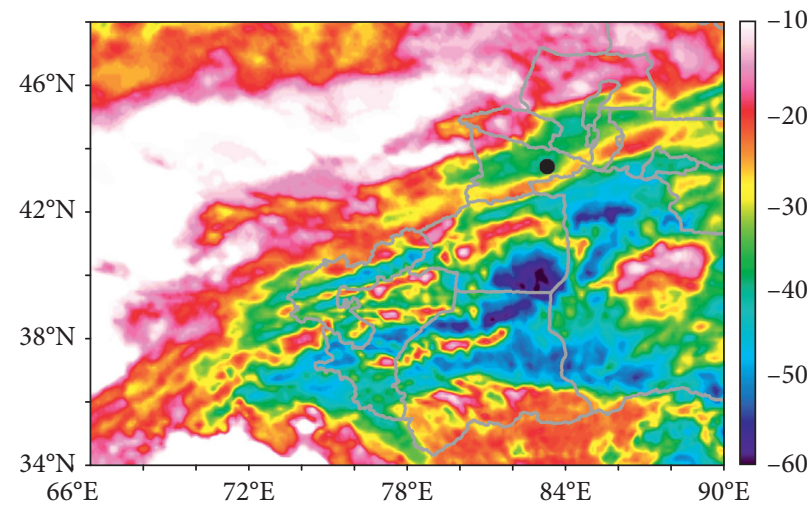

(c)

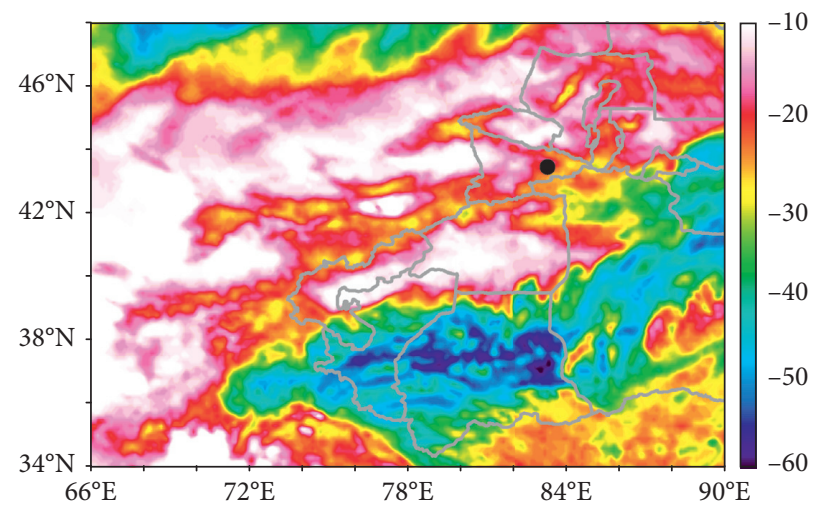

(e)

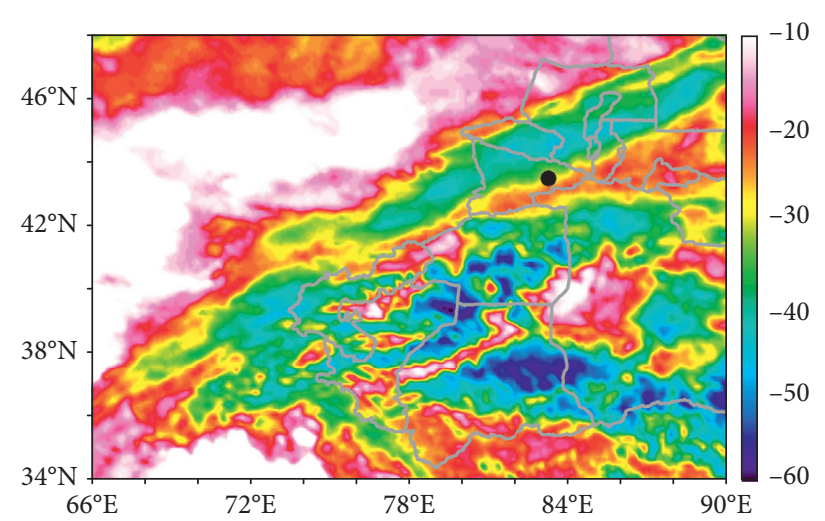

(b)

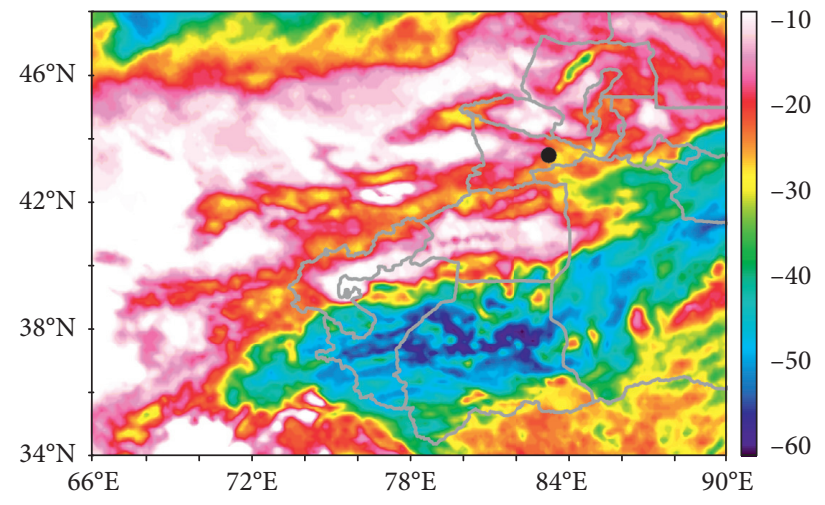

(d)

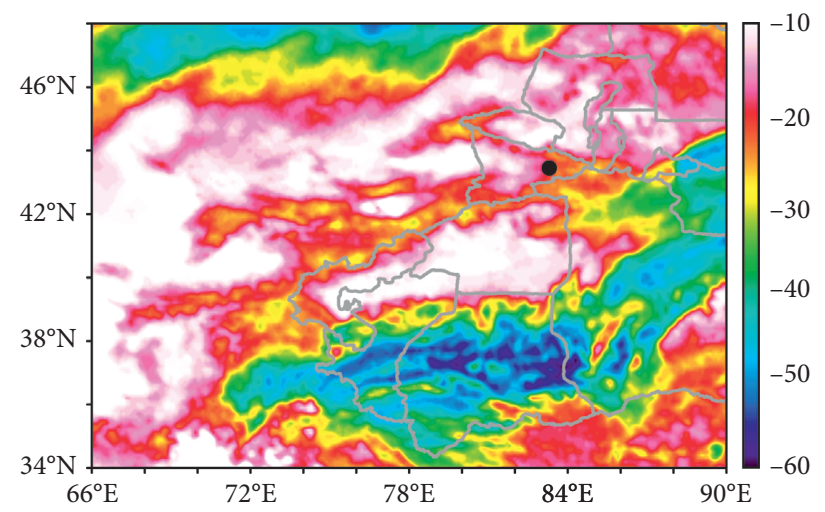

(f)

FIGURE 5: Evolution of TBB of FY-2G: (a) at 12:00 on February 18, (b) at 16:00 on February 18, (c) at 19:00 on February 18, (d) at $00: 00$ on February 19, (e) at $01: 00$ on February 19, and (f) at 02:00 on February 192020.

and the strongest reflectivity factor greater than $23 \mathrm{dBz}$ was below $1 \mathrm{~km}$. The strong reflectance factor from $11: 00$ to 23 : 00 on the 18th corresponds to the strong snowfall period in Figure 2 during that period, and the subsequent weak reflectance factor corresponds to the subsequent weaker snowfall. Therefore, the reflectance factor had a good early warning effect on the beginning, end, and intensity of the snowstorm. Simultaneously, the height of the reflectivity factor gradually decreased during the snowstorm, indicating that the height of the cloud top gradually decreased during the snowstorm, which was consistent with the results observed in TBB of FY-2G in Figure 5.
Figure $8(\mathrm{~b})$ is the time-height profile of the particle radius of the millimeter-wave cloud radar during the snowstorm. At $00: 00$ on February 18, when the snowstorm was approaching, the particle radius developed less than $30 \mu \mathrm{m}$ upward and downward simultaneously from $4 \mathrm{~km}$. During the snowstorm process, the particles collided and grow during the falling process, and the particle radius gradually increased. The largest particle radius was below $1 \mathrm{~km}$, corresponding to the maximum reflectance factor. Similar to the relationship between reflectivity factor and snowfall intensity, the period of appearance of large particle radius coincided with the period of strong snowfall, and then 


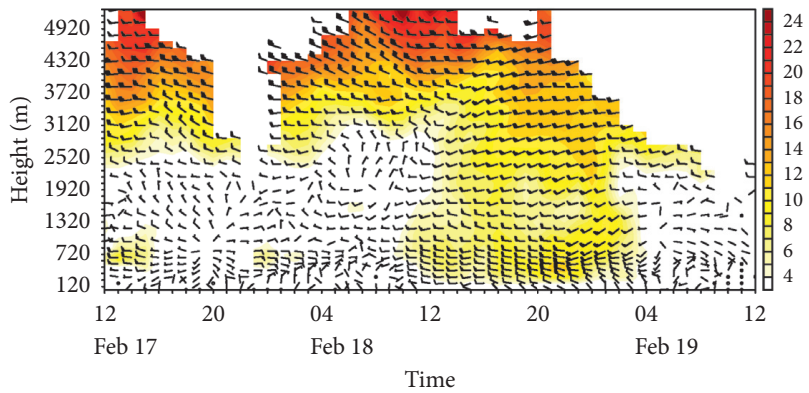

(a)

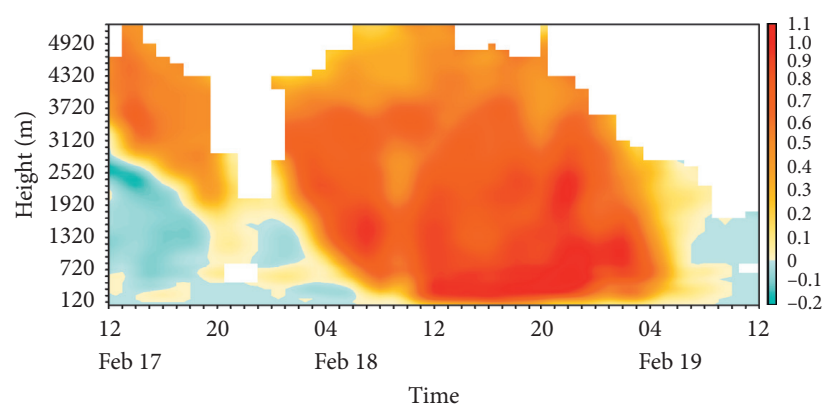

(b)

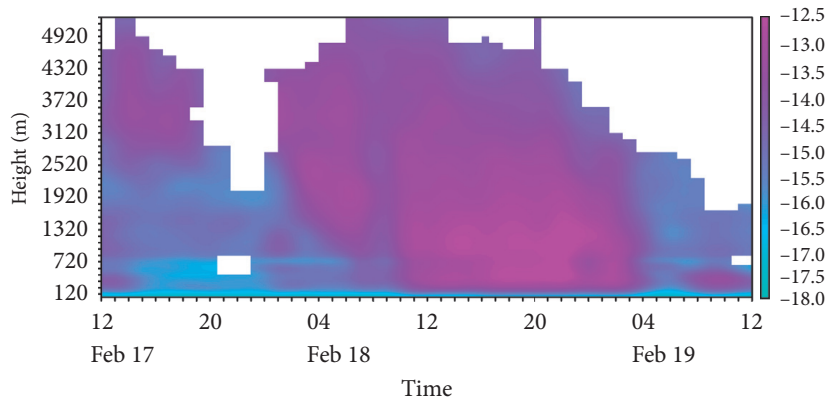

(c)

Figure 6: Time-height profile of radar wind profiler data: (a) horizontal wind (shadow; unit, $\mathrm{ms}^{-1}$ ), (b) vertical velocity (shadow; unit, ms ${ }^{-1}$ ), and (c) natural logarithm of the atmospheric refractive index structure constant (shadow).

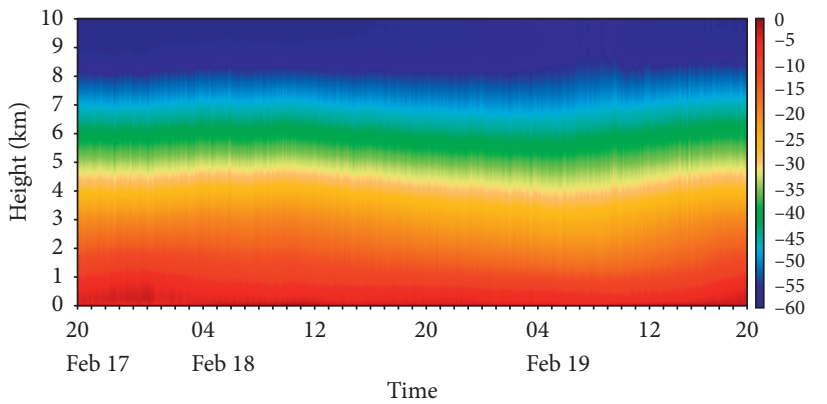

(a)

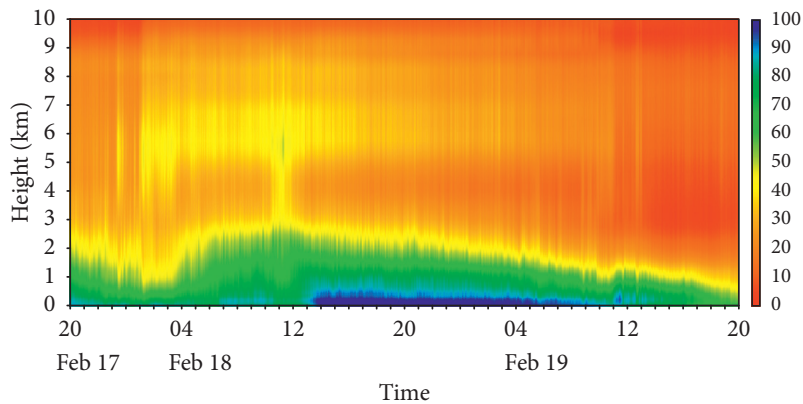

(c)

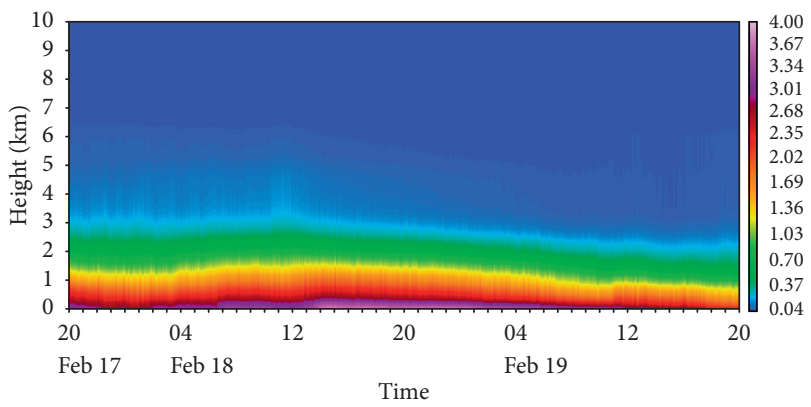

(b)

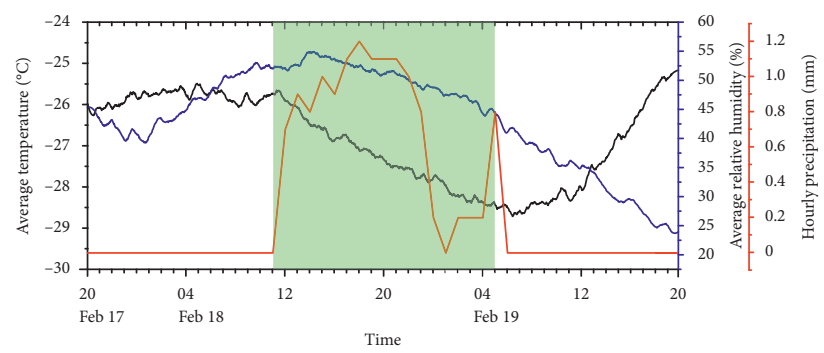

(d)

Figure 7: Time-height profile of ground-based microwave radiometer data: (a) temperature (shaded; unit, ${ }^{\circ} \mathrm{C}$ ), (b) water vapor density (shaded; unit, $\mathrm{g} \mathrm{kg}^{-1}$ ), (c) relative humidity (shaded; unit, \%), and (d) average temperature, average relative humidity of the entire atmosphere, and hourly precipitation evolution. 


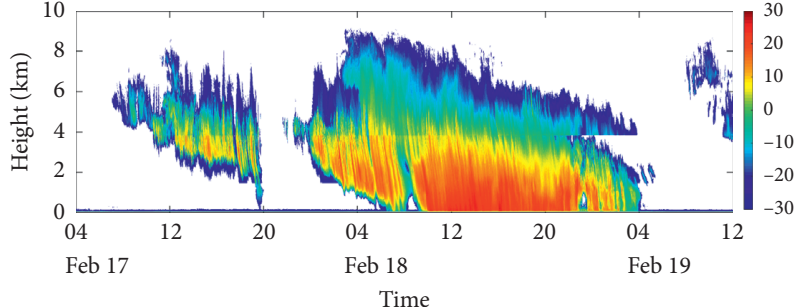

(a)

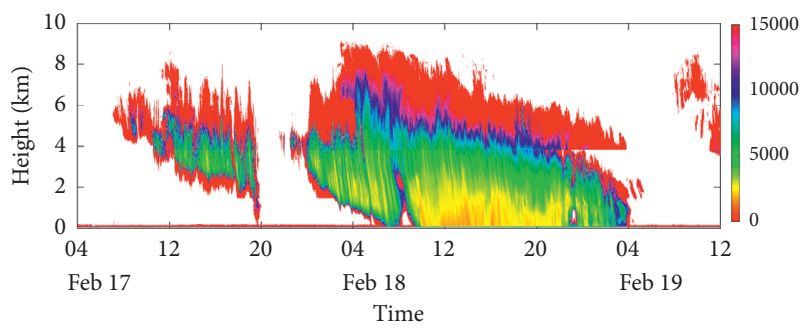

(c)

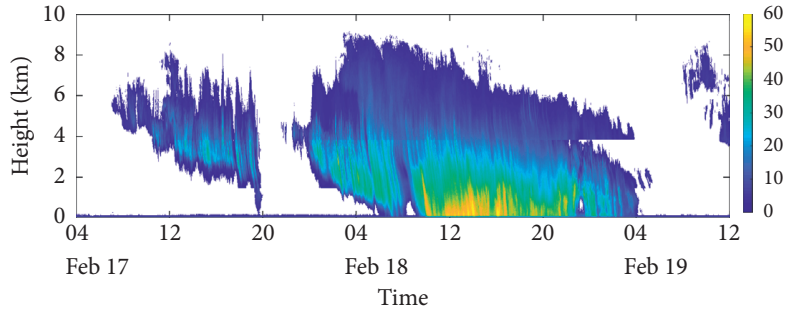

(b)

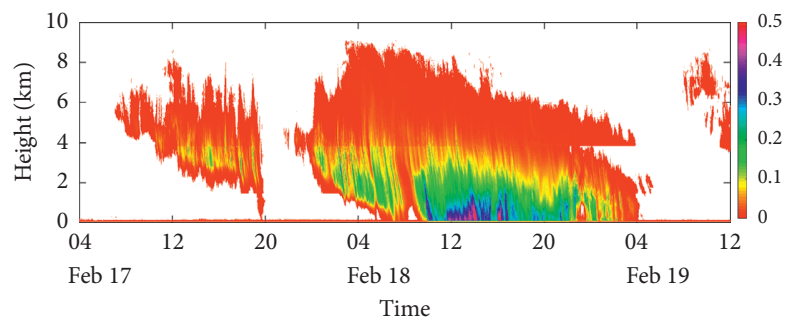

(d)

FIGURE 8: Time-height profile of millimeter-wave cloud radar data: (a) reflectivity factor (shaded; unit, dBz), (b) particle radius (shaded; unit, $\mu \mathrm{m})$, (c) unit volume number concentration (shaded; unit, per $\mathrm{mm}^{-3}$ ), and (d) ice water content (shaded; unit, $\mathrm{g} \mathrm{m}^{-3}$ ).

the particle radius and snowfall intensity also decreased at the same time.

Figure $8(\mathrm{c})$ is the time-height profile of the unit volume number concentration of the millimeter-wave cloud radar during the snowstorm. After the start of the snowstorm, the unit volume number concentration developed upward and downward simultaneously, and the unit volume number concentration varied from 1200 to 15000 per $\mathrm{mm}^{-3}$. During the snowstorm, the unit volume number concentration and the particle radius changed oppositely, that is, the particle radius gradually increased from high altitude to the ground during the falling process, while the concentration gradually decreased; combined with the large reflectivity factor of the lower layer, it can be seen that large particles have a major contribution to the reflectivity factor.

Figure $8(d)$ is the time-height profile of the ice water content in the millimeter-wave cloud radar during the snowstorm. The ice water content during the snowstorm was below $0.5 \mathrm{~g} \mathrm{~m}^{-3}$, and the large value of the ice water content was mainly below $2 \mathrm{~km}$, reaching 0.3 to $0.5 \mathrm{~g} \mathrm{~m}^{-3}$, and the ice water content above $4 \mathrm{~km}$ was mainly less than $0.1 \mathrm{~g} \mathrm{~m}^{-3}$. As a physical quantity related to moisture, the period of large value of ice water content was consistent with the period of strong snowfall, and, in the subsequent stage when ice water decreased, the snowfall intensity also decreased. Other physical quantities related to moisture included the specific humidity indicated by the reanalysis data in Figure 4, and the water vapor density and relative humidity obtained by the ground-based microwave radiometer in Figure 7 also indicated that water vapor was mainly concentrated in the lower atmosphere below $2 \mathrm{~km}$ during the snowstorm. These physical quantities related to moisture increased significantly at the lower level before the snowstorm started, which could be used as an early warning signal for snowstorm about 8 hours in advance. Similarly, the four physical quantities obtained from the millimeter-wave cloud radar began to appear at $4 \mathrm{~km}$ earlier than the occurrence of the snowstorm about 12 hours, which can also be used as a warning signal for the snowstorm.

\section{Discussion}

Snowstorms mainly occurred in the northern China in winter, and Xinjiang was a snowstorm center. Excessive snowstorm often brought about great impact and harm to local agriculture and animal husbandry production and people's lives. However, in the past, the research on snowstorm mainly focused on weather-scale analysis, and the research and understanding of the macro and micros structures of clouds and snowfall particles during snowstorms were very inadequate in Xinjiang [40]. Previous studies have shown that terrain plays an important role in snowstorms in Xinjiang, and the snowstorm centers in Xinjiang are all located near the mountains [41], and different atmospheric circulations divide Xinjiang snowstorms into warm front snowstorms in the Altay region and the Tacheng-Emin basin and cold front snowstorm in the Yili region and the region of northern Xinjiang along the Tianshan Mountains [40, 44, 45]. Zhuang et al. [40] pointed out that there are significant differences in the circulation situation of these two types of snowstorms, but their differences only carry out comparative studies on a small number of cases and lack systematic studies. Some meaningful conclusions have been obtained from some case analysis, warm front snowstorm and cold front snowstorm are caused by warm front system and cold front system respectively [45], and warm front snowstorm occurs in the decompression and heating zone on the ground, while cold front snowstorm is the opposite. Simultaneously, atmospheric instability during cold front snowstorms is 
significantly stronger than warm front snowstorms [46]. The above studies have provided a meaningful basis for the forecast of snowstorms in Xinjiang, but, due to the limitations of observational instruments, no more research on the refined structure of snowstorms has been carried out. Wang et al. [38, 39] used radar wind profiler and microwave radiometer to conduct research on snowstorm in Urumqi, Xinjiang. Their research helped reveal the fine structure of snowstorm in Xinjiang, and the in-depth analysis of radar wind profiler also provided ideas for the early warning of snowstorm in Xinjiang. However, the lack of millimeterwave cloud radar limits the study of clouds and snow particles during snowstorms. Comprehensive and diverse observational data are one of the most important reasons restricting the refined research of Xinjiang snowstorm, which not only made it impossible to reveal the microphysical characteristics of clouds and snowfall but also made the microphysical scheme in the numerical model very uncertain; more importantly, it will be difficult to improve early warning capabilities of snowstorm under insufficient observational data, which eventually led to certain deviations and difficulties in snowfall forecasting and early warning.

The dynamic process and cloud microphysical characteristics of Xinjiang snowstorm were significantly different from those in other parts of China. During heavy snowstorms in central and northern China, there was a clear southwestern warm and humid airflow at $700 \mathrm{hPa}$, which merged with the northern cold air during the northward process and formed a convergence line and was uplifted, and the northern cold air acted as a cold cushion during the process [46-48]. The warm and humid southwest air not only provided the dynamic convergence conditions for the snowstorm but also brought about a lot of water vapor to the snowstorm [49, 50]. In the Jianghuai area of China, cold air from the north and warm and humid air from the southwest still existed during the snowstorm, and the easterly warm and humid air from the ocean also played a key role in the occurrence and enhancement of the snowstorm [51, 52]. This type of snowfall involved the warm and humid southwestern air currents, usually caused by backflow conditions, extratropical cyclones, shear lines, and low trough cold front weather systems [53]. The other type was the sea-effect snowfall produced when strong cold air flowed through the warm sea, which mainly occurred in coastal areas of middle and high latitudes, with the Shandong Peninsula being the most prominent [54-56]. In comparison, the water vapor in the arid region of Xinjiang is obviously insufficient compared to the central and eastern China in the monsoon region. More importantly, the southern part of Yili is the main mountain range of the Tianshan Mountains above $3000 \mathrm{~m}$, and it stretches westward to Kyrgyzstan and other countries. Therefore, the snowstorm process in the Yili area is affected by insufficient water vapor and complex terrain, and it is impossible to have the strong warm and humid southwest jet at $700 \mathrm{hPa}$ as in central and eastern China. The forecast and early warning of the snowstorm in Yili area should pay more attention to the blocking and uplifting effect of the low-level westerly airflow into the trumpet terrain formed by the Tianshan Mountains.
Zhuang et al. [37] pointed out that, during the snowstorm in January 28, 2014, the southwest low-level jet could be strengthened, with a large amount of warm and humid air transporting to the snowstorm area in Xinjiang. However, it is worth noting that the southwest warm and humid jet referred to in their research is different from that of central and eastern China. First of all, the low-level jet they mentioned is significantly smaller than the low-level jet in central and eastern China in terms of scale, and it is only a smalland medium-scale system. Secondly, strictly speaking, the low-level jet they mentioned should be called the westward jet, and this jet moved eastward under the influence of the Tianshan Mountains. Similarly, during the snowstorm in the region of northern Xinjiang along the Tianshan Mountains, the southwest low-altitude jet cannot exist because the snowstorm area is adjacent to the north side of the Tianshan Mountains, just as Wang et al. [38, 39] found that the low altitude during the snowstorm in this area was northwest or northerly airflow. Therefore, the dynamic process of the snowstorm in this study is significantly different from the snowstorm in central and eastern China and the sea-effect snowfall. The arid area background and unique topography also made the cloud microphysical characteristics during the snowstorm in Xinjiang different from the snowstorm accompanied by warm and humid airflow from southwest China and the sea-effect snowfall. The height of the hydrometeor particles in the sea-effect snowstorm was below $600 \mathrm{hPa}$, and the maximum appeared at $900-850 \mathrm{hPa}$, which corresponded to the shallow convective structure [57, 58]. Hydrometeor particles could reach a height of $9 \mathrm{~km}$ during a snowstorm in Xinjiang. At the same time, the hydrometeor particle radius and particle water content during the snowstorm in the central and eastern regions were larger than in Xinjiang [59-61]. Wang et al. [38, 39] calculated the equivalent reflectivity factor using radar wind profiler data and showed that the equivalent reflectivity factor during the snowstorm in Urumqi, Xinjiang, is closely related to the beginning, end, and intensity of the snowstorm, which is consistent with reflectivity factor in our research using millimeter-wave cloud radar. However, many studies [31-34] have shown that millimeter-wave cloud radar has advantages in studying the microphysics of clouds and snow during snowstorms. However, it should be noted that this article is only a case study of a typical snowstorm process in Yili, Xinjiang; whether the conclusions obtained are applicable to other arid regions in China still needs to be verified by more snowstorms in the future. In any case, this is the first comprehensive study of snowstorm using millimeter-wave cloud radar combined with other fine observation data in Xinjiang, laying the foundation for further research.

\section{Conclusions}

In this study, a snowstorm in the Yili region of Xinjiang was studied based on a variety of observational data, including data from FY-2G, a radar wind profiler, a ground-based microwave radiometer, and a millimeter-wave cloud radar during the Central Asia Extreme Precipitation Observation Test (CAEPOT). By analyzing the macroscopic 
characteristics and microphysical changes in the snowstorm system, the following main conclusions were obtained:

(1) The snowstorm process occurred in the favorable circulation background resulting from the eastward movement of a low trough. The water vapor, heat, and power conditions were well coordinated, which was extremely beneficial to the occurrence of a snowstorm. Unlike other parts of China, there were no strong southwestern warm and humid air flow during this snowstorm. For this snowstorm, the flared terrain formed by Tianshan Mountains has an important dynamic effect on the snowstorm.

(2) Before the snowstorm process, the horizontal wind field drastically changed in the vertical direction, exacerbating the atmospheric instability, and there was upward movement in the lower atmosphere, which was conducive to the occurrence of a snowstorm. During the snowstorm, the horizontal wind speed and vertical speed were obviously enhanced, and the physical quantities related to moisture further increased. The low-level convergence line and the middle-level trough were the key systems for the snowstorm. The snowstorm process was accompanied by cold advection, a maximum sinking velocity of $1.1 \mathrm{~ms}^{-1}$ below $2520 \mathrm{~m}$, and a natural logarithm of the maximum atmospheric refractive index structure constant of -12.5 .

(3) After the start of the snowstorm, the temperature of the entire atmosphere decreased, and the temperature decrease trend continued until approximately $2 \mathrm{~h}$ after the end of the snowstorm. The water vapor density was mainly concentrated below $1.5 \mathrm{~km}$, and the maximum value of the water vapor density in the near-surface layer below $0.5 \mathrm{~km}$ exhibited good correspondence with the snowfall intensity. The relative humidity area above $50 \%$ was located below $3 \mathrm{~km}$, and the height of the relative humidity area above $50 \%$ gradually decreased. The $100 \%$ relative humidity area was located in the near-surface layer below $0.5 \mathrm{~km}$, and the relative humidity in the nearsurface layer reached $100 \%$ approximately $2 \mathrm{~h}$ after the start of the snowstorm. Due to cold advection during the snowstorm, the average temperature of the entire atmosphere showed a decreasing trend, with a temperature decrease of $2^{\circ} \mathrm{C}$. The average relative humidity first increased and then decreased, and the relative humidity varied from $45 \%$ to $55 \%$.

(4) Approximately $3 \mathrm{~h}$ before the start of the snowstorm, the reflectivity factor, particle radius, unit volume number concentration, and ice water content of the millimeter-wave cloud radar began to develop upward and downward simultaneously from $4 \mathrm{~km}$. During the snowstorm, the reflectivity factor was between $-30 \mathrm{dBz}$ and $30 \mathrm{dBz}$, the strong reflectivity factor greater than $6 \mathrm{dBz}$ was below $4 \mathrm{~km}$, and the strongest reflectivity factor greater than $23 \mathrm{dBz}$ was below $1 \mathrm{~km}$. During the snowstorm, the particle radius was less than $60 \mu \mathrm{m}$. During the falling process, the particles touched and grew, and the particle radius gradually increased. The larger particles from 30 to $60 \mu \mathrm{m}$ were located below $4 \mathrm{~km}$, and the largest particles from 50 to $60 \mu \mathrm{m}$ were located below $1 \mathrm{~km}$. During the snowstorm, the unit volume number concentration varied from 1200 to 15000 per $\mathrm{mm}^{-3}$. As the reflectivity factor and particle radius increased, the unit volume number concentration decreased. During the snowstorm, the ice water content was below $0.5 \mathrm{~g} \mathrm{~m}^{-3}$. The large values of the ice water content were mainly below $4 \mathrm{~km}$, reaching 0.1 to $0.5 \mathrm{~g} \mathrm{~m}^{-3}$. The ice water content above $4 \mathrm{~km}$ was mainly less than $0.1 \mathrm{~g} \mathrm{~m}^{-3}$. The ice water content, reflectivity factor, particle radius, and unit volume number concentration appeared in the same period as the snowfall.

\section{Data Availability}

Data used in this paper can be provided by Yong Zeng (15099610397@163.com) upon request.

\section{Conflicts of Interest}

The authors declare no conflicts of interest.

\section{Acknowledgments}

This research was funded by the National Key Research and Development Program of China (2018YFC1507102 and 2018YFC1507104) and Basic Business Expenses (IDM2019001).

\section{References}

[1] B. B. Balsley, W. L. Ecklund, D. A. Carter, A. C. Riddle, and K. S. Gage, "Average vertical motions in the tropical atmosphere observed by a radar wind profiler on pohnpei $\left(7^{\circ} \mathrm{N}\right.$ latitude, $157^{\circ} \mathrm{E}$ longitude)," Journal of the Atmospheric Sciences, vol. 45, no. 3, pp. 396-405, 1988.

[2] W. M. Angevine, "Errors in mean vertical velocities measured by boundary layer wind profilers," Journal of Atmospheric and Oceanic Technology, vol. 14, no. 3, pp. 565-569, 1997.

[3] P. T. May and D. K. Rajopadhyaya, "Vertical velocity characteristics of deep convection over Darwin, Australia," Monthly Weather Review, vol. 127, no. 6, pp. 1056-1071, 1999.

[4] M. Lothon, B. Campistron, S. Jacoby-Koaly et al., "Comparison of radar reflectivity and vertical velocity observed with a scannable C-band doppler radar and two UHF profilers in the lower troposphere," Journal of Atmospheric Oceanic Technology, vol. 19, no. 3, pp. 899-910, 2002.

[5] Z. Vaughan and R. M. Worthington, "Inertia-gravity waves observed by the UK MST radar," Quarterly Journal of the Royal Meteorological Society, vol. 133, no. 2, pp. 179-188, 2007.

[6] G. M. Barnes, E. J. Zipser, D. Jorgensen, and F. Marks, "Mesoscale and convective structure of a hurricane rainband," 
Journal of the Atmospheric Sciences, vol. 40, no. 9, pp. 21252137, 1983.

[7] R. Cifelli and S. A. Rutledge, "Vertical motion structure in maritime continent mesoscale convective systems: results from a 50-MHz profiler," Journal of the Atmospheric Sciences, vol. 51, no. 18, pp. 2631-2652, 1994.

[8] L. Kanofsky and P. Chilson, "An analysis of errors in drop size distribution retrievals and rain bulk parameters with a UHF wind profiling radar and a two-dimensional video disdrometer," Journal of Atmospheric and Oceanic Technology, vol. 25, no. 12, pp. 2282-2292, 2008.

[9] D. K. Rajopadhyaya, S. K. Avery, P. T. May, and R. C. Cifelli, "Comparison of precipitation estimation using single- and dual-frequency wind profilers: simulations and experimental results," Journal of Atmospheric and Oceanic Technology, vol. 16, no. 1, pp. 165-173, 1999.

[10] J. Röttger, "Structure and dynamics of the stratosphere and mesosphere revealed by VHF radar investigations," Pure and Applied Geophysics, vol. 118, no. 1, pp. 494-527, 1980.

[11] W. L. Ecklund, K. S. Gage, and C. R. Williams, "Tropical precipitation studies using a $915-\mathrm{MHz}$ wind profiler," Radio Science, vol. 30, no. 4, pp. 1055-1064, 1995.

[12] K. S. Gage and G. D. Nastrom, "Relationship of precipitation to vertical motion observed directly by a VHF wind profiler during a spring upslope storm near Denver, Colorado," Bulletin of the American Meteorological Society, vol. 66, no. 4, pp. 394-397, 1985.

[13] B. Balsley and V. L. Peterson, "Doppler-radar measurements of clear air atmospheric turbulence at $1290 \mathrm{MHz}$," Journal of Applied Meteorology, vol. 20, no. 3, pp. 266-274, 1981.

[14] W. K. Hocking, "Measurement of turbulent energy dissipation rates in the middle atmosphere by radar techniques: a review," Radio Science, vol. 20, no. 6, pp. 1403-1422, 1985.

[15] W. M. Angevine, A. B. White, and S. K. Avery, "Boundarylayer depth and entrainment zone characterization with a boundary-layer profiler," Boundary-Layer Meteorology, vol. 68, no. 4, pp. 375-385, 1994.

[16] E. E. Gossard, D. E. Wolfe, K. P. Moran, R. A. Paulus, K. D. Anderson, and L. T. Rogers, "Measurements of clear-air gradients and turbulence properties with radar wind profilers," Journal of Atmospheric and Oceanic Technology, vol. 15, no. 2, pp. 21-342, 1998.

[17] R. R. Braham, "The midwest snow storm of 8-11 december 1977," Monthly Weather Review, vol. 111, no. 2, pp. 253-272, 1983.

[18] A. Y. Chen, C. L. Li, and X. Y. Chen, "A comparison of heavy snow of formation in spring and winter," Meteorological Monthly, vol. 25, no. 3, pp. 37-39, 1999, in Chinese.

[19] D. H. Wang, C. J. Liu, Y. Liu et al., "A preliminary analysis of features and causes of the snow storm event over the southern China in January 2008," Acta Meteorologica Sinica.vol. 66, no. 2, pp. 405-422, 2008, in Chinese.

[20] P. W. Chan, "Performance and application of a multiwavelength, ground-based microwave radiometer in intense convective weather," Meteorologische Zeitschrift, vol. 18, no. 3, pp. 253-265, 2009.

[21] W. F. Feltz and J. R. Mecikalski, "Monitoring high-temporal-resolution convective stability indices using the ground-based atmospheric emitted radiance interferometer (AERI) during the 3 may 1999 Oklahoma-Kansas Tornado outbreak," Weather and Forecasting, vol. 17, no. 3, pp. 445-455, 2002.

[22] K. Friedrich, J. K. Lundquist, M. Aitken, E. A. Kalina, and R. F. Marshall, "Stability and turbulence in the atmospheric boundary layer: a comparison of remote sensing and tower observations," Geophysical Research Letters, vol. 39, no. 3, pp. 1-6, 2012.

[23] V. Mattioli, E. R. Westwater, D. Cimini et al., "Analysis of radiosonde and ground-based remotely sensed PWV data from the 2004 North Slope of Alaska Arctic winter radiometric experiment," Journal of Atmospheric and Oceanic Technology, vol. 24, no. 3, pp. 415-431, 2007.

[24] R. Ware, R. Carpenter, J. Guldner et al., "A multichannel radiometric profiler of temperature, humidity, and cloud liquid," Radio Science, vol. 38, no. 4, pp. 1-13, 2003.

[25] K. R. Knupp, T. Coleman, D. Phillips et al., "Ground-based passive microwave profiling during dynamic weather conditions," Journal of Atmospheric and Oceanic Technology, vol. 26, no. 6, pp. 1057-1073, 2009.

[26] H. E. Revercomb, D. D. Turner, D. C. Tobin et al., "The arm program's water vapor intensive observation periods," Bulletin of the American Meteorological Society, vol. 84, no. 2, pp. 217-236, 2003.

[27] K. P. Moran, B. E. Martner, M. J. Post, R. A. Kropfli, D. C. Welsh, and K. B. Widener, "An unattended cloudprofiling radar for use in climate research," Bulletin of the American Meteorological Society, vol. 79, no. 3, pp. 443-455, 1998.

[28] S. M. Sekelsky, W. L. Ecklund, J. M. Firda, K. S. Gage, and R. E. McIntosh, "Particle size estimation in ice-phase clouds using multifrequency radar reflectivity measurements at 95, 33, and $2.8 \mathrm{GHz}$," Journal of Applied Meteorology, vol. 38, no. 1, pp. 5-28, 1999.

[29] S. Y. Matrosov, M. D. Shupe, and I. V. Djalalova, "Snowfall retrievals using millimeter-wavelength cloud radars," Journal of Applied Meteorology and Climatology, vol. 47, no. 3, pp. 769-777, 2008.

[30] L. Liao, R. Meneghini, A. Tokay, and L. F. Bliven, "Retrieval of snow properties for $\mathrm{Ku}$ - and Ka-band dual-frequency radar," Journal of Applied Meteorology and Climatology, vol. 55, no. 9, pp. 1845-1858, 2016.

[31] L. P. Liu, L. Xie, and Z. H. Cui, "Examination and application of doppler spectral density data in drop size distribution retrieval in weak precipitation by cloud radar," Chinese Journal of Atmospheric Sciences, vol. 38, no. 2, pp. 223-236, 2014, in Chinese.

[32] L. Peng, H. B. Chen, and B. Li, "A case study of deriving vertical air velocity from 3-mm cloud radar," Chinese Journal of Atmospheric Sciences, vol. 36, no. 1, pp. 1-10, 2012, in Chinese.

[33] D. W. Wang, L. P. Liu, and R. Zong, "Fuzzy logic method in retrieval atmospheric cloud particle phases and effect analysis," Meteorological Monthly, vol. 41, no. 4, pp. 171-181, 2015, in Chinese.

[34] J. X. Wu, M. Wei, and J. Zhou, "Echo and capability analysis of $94 \mathrm{GHz}$ cloud radars," Acta Meteorologica Sinica, vol. 72, no. 2, pp. 402-416, 2014, in Chinese.

[35] F. Chen, Z. Yu, M. Yang et al., "Holocene moisture evolution in arid central Asia and its out-of-phase relationship with Asian monsoon history," Quaternary Science Reviews, vol. 27, no. 3-4, pp. 351-364, 2008.

[36] W. Huang, S. Feng, J. Chen, and F. Chen, "Physical mechanisms of summer precipitation variations in the Tarim Basin in Northwestern China," Journal of Climate, vol. 28, no. 9, pp. 3579-3591, 2015.

[37] X. C. Zhuang, J. X. Qin, and B. Y. Li, "Mesoscale characteristics of a snowstorm in western Xinjiang in 2014," Journal 
of Arid Meteorology, vol. 34, no. 2, pp. 326-334, 2016, in Chinese.

[38] M. Wang, W. Wei, Q. He et al., "Analyses on integrated detection of the blizzard process in 19-20 March 2012 in Urumqi, Xinjiang China," Meteorology and Atmospheric Physics, vol. 125, no. 1-2, pp. 63-73, 2014.

[39] M. Z. Wang, W. S. Wei, Q. He et al., "Application of boundary layer wind-profiling radar data to a springtime snowstorm analysis in Urumqi," Meteorological Applications, vol. 20, pp. 10-19, 2013.

[40] X. C. Zhuang, B. Y. Li, R. Q. Li, and H. K. Zhou, "Some advances on study of strong snowfall in northern Xinjiang," Desert and Oasis Meteorology, vol. 10, no. 2, pp. 1-8, 2016, in Chinese.

[41] J. B. Zhang and Z. F. Deng, A Generality of Rainfall in Xinjiang, Meteorological Press, Beijing, China, 1987, in Chinese.

[42] L. W. Uccellini and D. R. Johnson, "The coupling of upper and lower tropospheric jet streaks and implications for the development of severe convective storms," Monthly Weather Review, vol. 107, no. 6, pp. 682-703, 1979.

[43] G. X. Wu, Y. P. Cai, and X. Q. Tang, "Moist potential vorticity and slantwise vorticity development," Acta Meteorologica Sinica, vol. 53, no. 4, pp. 387-405, 1995, in Chinese.

[44] R. Q. Li, Y. Tang, and A. J. Rouzi, "Atmospheric circulation and water vapor characteristics of snowstorm anomalies in northern Xinjiang in 2010," Plateau Meteorology, vol. 34, no. 1, pp. 155-162, 2015, in Chinese.

[45] X. C. Zhuang, B. Y. Li, and C. Y. Chen, "Analysis of a snowstorm weather process in a coexisting warm area and cold front in northern Xinjiang," Climatic and Environmental Research, vol. 21, no. 1, pp. 17-28, 2016, in Chinese.

[46] X. C. Zhuang, H. K. Zhou, and B. Y. Li, "Forecast test of T639 model on heavy snowfall in warm area of northern Xinjiang," Journal of Arid Meteorology, vol. 33, no. 6, pp. 1031-1037, 2015, in Chinese.

[47] L. S. Feng, P. Song, and F. Zheng, "Diagnostic analysis of a severe regional snowstorm event in the early winter of 2016 in Henan province, China," Chinese Journal of Atmospheric Sciences, vol. 44, no. 1, pp. 13-26, 2020, in Chinese.

[48] J. J. Wang and W. L. Zhang, "Formation mechanism of the snowstorm over Beijing in early winter of 2009," Journal of Applied Meteorology, vol. 22, no. 4, pp. 398-410, 2011, in Chinese.

[49] X. Z. Chen, J. L. Mu, and G. X. Zhao, "Analysis of jet stream characteristic during the snowstorm process in North China," Plateau Meteorology, vol. 33, no. 4, pp. 1069-1075, 2014, in Chinese.

[50] J. Li, S. X. Zhao, and J. H. Sun, "Analysis of a record heavy snowfall event in North China," Climatic and Environmental Research, vol. 22, no. 6, pp. 683-698, 2017, in Chinese.

[51] C. Y. Sheng and X. X. Yang, "One weather process analysis of blizzard caused by Jiang-huai cyclone," Journal of Shandong Meteorology, vol. 21, no. 4, pp. 10-11, 2001, in Chinese.

[52] Y. Zhao, H. Q. Zhu, and X. Lan, "Structure of the snowstorm cloud associated with northward Jiang-Huai cyclone based on cloudsat satellite data," Chinese Journal of Geophysics, vol. 61, no. 12, pp. 4789-4804, 2018, in Chinese.

[53] J. H. Fan and X. Y. Yi, "Comparative analysis of several influencing systems in the process of a large-scale continuous snowstorm," Acta Meteorologica Sinica, vol. 77, no. 6, pp. 965-979, 2019, in Chinese.

[54] C. F. Yang, S. L. Zhou, and L. Chang, "Case study of the cause and the dynamic structure for a small-scale snowstorm event associated with a cyclone," Acta Meteorologica Sinica, vol. 73, no. 6, pp. 1039-1051, 2015, in Chinese.

[55] J. H. Sun and C. Y. Huang, "The three-dimensional structure of coastal front producing heavy snow over the Shandong Peninsula," Chinese Journal of Atmospheric Sciences, vol. 35, no. 1, pp. 1-15, 2011, in Chinese.

[56] Y. X. Zhang, R. Q. Hou, and S. B. Zhang, "Numerical experiments and diagnosis on a heavy snow of return-flow events," Meteorological Monthly, vol. 33, no. 9, pp. 25-32, 2007, in Chinese.

[57] X. J. Yu, X. Z. Gu, and H. L. Li, "Mesoscale numerical simulation and cloud microphysical characteristics of a cold air snowstorm in Shandong Peninsula," Meteorological Monthly, vol. 39, no. 8, pp. 955-964, 2013, in Chinese.

[58] Y. C. Chen, Y. L. Jin, and D. P. Ding, "Preliminary analysis on the application of millimeter wave cloud radar in snow observation," Chinese Journal of Atmospheric Sciences, vol. 42, no. 1, pp. 134-149, 2018, in Chinese.

[59] Y. Huang, X. L. Guo, and K. Bi, "Vertical observation and numerical simulation of the clouds physical characteristics of snow-producing over Yanqing Mountain area in Beijing," Chinese Journal of Atmospheric Sciences, vol. 44, no. 2, pp. 356-370, 2020, in Chinese.

[60] Q. Gao, X. L. Guo, and X. E. Liu, "Numerical simulation and observation study on microphysical formation processes of two different snowfall cases in Northern Mountain area of Beijing," Chinese Journal of Atmospheric Sciences, vol. 44, no. 2, pp. 407-420, 2020, in Chinese.

[61] X. C. Jia, X. C. Ma, and K. Bi, "Distributions of particle size and fall velocities of winter precipitation in Beijing," Acta Meteorologica Sinica, vol. 76, no. 1, pp. 148-159, 2018, in Chinese. 